\title{
Erratum to: Vocal Patterns in Infants with Autism Spectrum Disorder: Canonical Babbling Status and Vocalization Frequency
}

\author{
Elena Patten • Katie Belardi • Grace T. Baranek • \\ Linda R. Watson · Jeffrey D. Labban • \\ D. Kimbrough Oller
}

Published online: 13 August 2014

(c) Springer Science+Business Media New York 2014

\section{Erratum to: J Autism Dev Disord \\ DOI 10.1007/s10803-014-2047-4}

Due to an oversight, the original acknowledgment section did not include all of the relevant funding information. An amended acknowledgment is presented below.

Acknowledgments This research was made possible through a grant from the National Institute for Child Health and Human Development (R01-HD42168) and a Grant from Cure Autism Now Foundation (Sensory-Motor and Social-Communicative Symptoms of Autism in Infancy). It was also supported by grants from the National Institute on Deafness and Other Communication Disorders (R01 DC006099 and R01 DC011027). The content is solely the responsibility of the authors and does not necessarily represent the official views of the National Institutes of Health. We thank the families whose participation made this study possible and the staff who collected and processed data for this project.

The online version of the original article can be found under doi:10. 1007/s10803-014-2047-4.

\section{E. Patten $(\square)$}

Department of Communication Sciences and Disorders,

University of North Carolina, Greensboro, 300 Ferguson

Building, Greensboro, NC 27402-6170, USA

e-mail: e_patten@uncg.edu

K. Belardi · L. R. Watson

Department of Allied Health Sciences, University of North Carolina, Chapel Hill, Bondurant Hall, CB\#7190, Chapel Hill, NC 27599-7190, USA

\section{G. T. Baranek}

Department of Allied Health Sciences, University of North Carolina, Chapel Hill, Bondurant Hall, CB \#7122, Chapel Hill, NC 27599-7122, USA

J. D. Labban

University of North Carolina, Greensboro, 231 HHP Building, Greensboro, NC 27412, USA

D. K. Oller

The University of Memphis, 807 Jefferson Avenue, Memphis, TN 38105, USA

D. K. Oller

Konrad Lorenz Institute for Evolution and Cognition Research, Klosterneuburg, Austria 